\title{
Sonographic evaluation of intra-abdominal organs in children with familial Mediterranean fever
}

\author{
๑Ergün Sönmezgöz ${ }^{1}$, ๑Fitnet Sönmezgöz ${ }^{2}$ \\ ${ }^{1}$ Gaziosmanpasa University, Faculty of Medicine Department of Pediatrics, Tokat, Turkey \\ ${ }^{2}$ Tokat Medical Park Hospital, Department of Radiology, Tokat, Turkey
}

Cite this article as: Sönmezgöz E, Sönmezgöz F. Sonographic evaluation of intra-abdominal organs in children with familial Mediterranean fever. J Health Sci Med 2021; 4(5): 662-665.

\begin{abstract}
Objective: The reticuloendothelial system is rarely assessed in patients with familial Mediterranean fever (FMF). We aimed to evaluate the size of the liver and spleen by ultrasonography in children and adolescents with FMF and compare it to their healthy peers.

Material and Method: Patient data were evaluated by height, weight, and age and compared with those of healthy controls.

Results: A total of 86 children with FMF diagnosed using the Turkish Pediatric Criteria and 54 healthy children were included. The extent of splenomegaly was $27.9 \%$ in the FMF group. The mean spleen length was $99.84 \pm 17.4 \mathrm{~mm}$ in patients and $93.44+15.49 \mathrm{~mm}$ in controls $(\mathrm{p}=0.03$ ). The mean liver length was $122.61 \pm 17.4 \mathrm{~mm}$ in patients and $117.71 \pm 16.04 \mathrm{~mm}$ in controls $(\mathrm{p}=0.104)$. FMF appears to affect spleen length independently of anthropometric data $(\mathrm{t}=2.182 ; \mathrm{p}=0.031)$. Splenomegaly was accompanied by the M694V (32.55\%, n=17) and E148Q (3.4\%, n=3) mutations.

Conclusion: FMF affects spleen length independently of anthropometric data. Splenomegaly may reflect subclinical inflammatory activity in FMF patients in remission. Spleen size can serve as a marker of subclinical inflammation during remission.
\end{abstract}

Keywords: Familial Mediterranean fever, ultrasonography, splenomegaly, children, inflammatory markers.

\section{INTRODUCTION}

Familial Mediterranean fever (FMF) is an acute, repetitive, and self-limiting autoinflammatory disease inherited in an autosomal-recessive manner and characterized by fever and abdominal, joint, and chest pain (1). FMF is caused by mutations in the MEFV gene located on the short arm of chromosome 16. The MEFV gene encodes pyrin, a genetic defect that increases the inflammatory response (2). Many MEFV mutations have been reported. Colchicine halts or limits FMF attacks in most patients and prevents the development of amyloidosis, which is the most serious complication (3). Few studies have explored the effects of FMF on the reticuloendothelial system (4). Splenomegaly, hepatomegaly, and lymphadenopathy have been reported in FMF patients $(5,6)$. Here, we measured the spleen and liver sizes of children with FMF who were in remission, as well as of healthy controls.

\section{MATERIAL AND METHOD}

The study was approved by the Gaziosmanpaşa University Clinical Researchs Ethics Committee (Date: 03.01.2016, Decision No: 16-KAEK-060). All procedures were carried out in accordance with the ethical rules and the principles of the Declaration of Helsinki.

A total of 86 FMF patients diagnosed using the Turkish pediatric criteria and 54 healthy children were included (7). Patients who had congenital anomaly, connective tissue diseases, metabolic, renal, endocrine and infectious diseases were excluded from the present study. Disease severity was determined using the modified Pras scoring system (8). Sonographic measurements of the liver and spleen were obtained during symptom-free periods by a radiologist with 10 years of experience using the Toshiba Aplio 500 platform (Toshiba Medical Systems, Tokyo, Japan) and 3.5-MHz pvt-375BT Convex Probe. Spleen 
measurements were made with subjects supine in a slightly right lateral decubitus position. The spleen was measured between the superomedial and inferolateral boundaries. Liver measurements were made in the supine position. The longitudinal axis was measured on the midclavicular plane. The upper edge (under the diaphragm dome) served as the upper margin and the bottom edge as the lower margin. The data were evaluated with reference to height, weight and age standards and compared with those of healthy controls. Informed consent was obtained from all participants or their parents before inclusion.

\section{Statistical Analysis}

The data were evaluated using SPSS version 19 software.

\section{RESULTS}

Patient ages ranged from 3 to 17 years. A total of 49 (57\%) were girls and $37(43 \%)$ boys. The mean age of FMF patients was 11.1 \pm 3.77 years and that of controls $10.21 \pm 4.13$ years $(\mathrm{p}=0.19)$. The mean body mass index of FMF patients was $18.01 \pm 4.1 \mathrm{~kg} / \mathrm{m}^{2}$ and that of controls $18.37 \pm 3.5 \mathrm{~kg} / \mathrm{m}^{2}(\mathrm{p}=0.59)$. The average age at diagnosis was $7.49 \pm 3.94$ years. The most common clinical findings were abdominal pain $(87.2 \%, \mathrm{n}=75)$, fever $(74.4 \%, \mathrm{n}=64)$, arthritis $(62 \%, n=54)$, chest pain $(30.2 \%, n=26)$, and an erysipelas-like rash $(5.8 \%, \mathrm{n}=5)$. The mean spleen length was $99.84 \pm 17.4 \mathrm{~mm}$ in FMF patients and 93.44 \pm 15.49 $\mathrm{mm}$ in controls $(\mathrm{p}=0.03)$. The mean liver length was $122.61 \pm 17.4 \mathrm{~mm}$ in patients and $117.71 \pm 16.04 \mathrm{~mm}$ in controls $(\mathrm{p}=0.104)$ (Table 1). The most common mutation was M694V (32.5\%, $\mathrm{n}=28)$. Splenomegaly was often accompanied by M694V (32.55\%, n=17) and E148Q mutations (3.4\%, $\mathrm{n}=3)$.

Spleen size (as revealed by sonography) was affected by FMF, being $5.355 \mathrm{~mm}$ greater (with statistical significance) in FMF patients than in controls when spleen length was considered a dependent variable $(\mathrm{t}=2.182 ; \mathrm{p}=0.031)($ Tables 2,3$)$.

\section{Statistical Analysis}

Continuous variables are shown as means with standard deviations and categorical variables as numbers with percentages. The average values of quantitative variables were compared. Cross-tables and the chi-squared test were used to compare qualitative variables. Pearson correlation coefficients between quantitative variables were calculated. A p-value $<0.05$ was considered to reflect statistical significance. Multivariate linear regression was used to explore the effects of selected variables on spleen and liver lengths. All calculations were made using IBM SPSS Statistics ver. 19 (SPSS Inc. and IBM Co., Somers, NY, USA).

\begin{tabular}{|lc|}
\hline \multicolumn{2}{|l|}{ Table 1. Demographic characteristics of FMF patients } \\
\hline Variables & Statistics \\
\hline Age, years & $10.76 \pm 3.9$ \\
Sex $(\mathrm{M} / \mathrm{F})$ & $64(45.7) / 76(54.3)$ \\
Weight, kg & $38.06 \pm 17.7$ \\
Height, cm & $140.59 \pm 22.0$ \\
BMI, kg/m² & $18.15 \pm 3.87$ \\
FMF familial history & $14(16.3)$ \\
Appendectomy history & $11(12.8)$ \\
Age at onset (years) & $6.05 \pm 3.8$ \\
Age at diagnosis (years) & $7.49 \pm 3.9$ \\
Severity score & $7.24 \pm 1.4$ \\
Liver length, mm & $120.7 \pm 17.3$ \\
Spleen length, mm & $97.4 \pm 18.1$ \\
\hline Data are shown as means \pm standard deviation or as numbers $(\%)$. \\
\hline
\end{tabular}

Table 2. Effects of age, height, weight, BMI, and FMF on spleen and liver measurements

\begin{tabular}{|llllll|}
\hline DV & IV & $\boldsymbol{\beta}$ & SD & t & p \\
\hline \multirow{5}{*}{ Spleen } & Age & 0.914 & 0.954 & 0.958 & 0.340 \\
& Weight & 0.096 & 0.396 & 0.243 & 0.808 \\
& Height & 0.127 & 0.284 & 0.445 & 0.657 \\
& BMI & 0.703 & 1.028 & 0.684 & 0.495 \\
& FMF & 5.355 & 2.454 & 2.182 & $0.031^{*}$ \\
& Age & -0.31 & 0.873 & -0.355 & 0.723 \\
& Weight & -0.274 & 0.364 & -0.754 & 0.452 \\
Liver & Height & 0.682 & 0.261 & 2.612 & $0.010^{*}$ \\
& BMI & 1.117 & 0.944 & 1.183 & 0.239 \\
& FMF & 3.657 & 2.252 & 1.624 & 0.107 \\
\hline $\begin{array}{l}\text { DV: dependent variable, IV: independent variable. } \\
\text { The effects of independent variables on dependent variables as revealed by a } \\
\text { multivariate linear regression model. *The difference was statistically significant. } \\
\text { Reference: control group. }\end{array}$
\end{tabular}

Table 3. Bivariate correlations between qualitative variables

\begin{tabular}{|lllccc|}
\hline & Variable & $\begin{array}{c}\text { Weight } \\
(\mathbf{k g})\end{array}$ & $\begin{array}{c}\text { Height } \\
(\mathbf{c m})\end{array}$ & $\begin{array}{c}\text { BMI } \\
\left(\mathbf{k g} / \mathbf{m}^{\mathbf{2}}\right)\end{array}$ \\
\hline \multirow{4}{*}{ FMF } & \multirow{2}{*}{ Liver } & $\mathrm{r}$ & 0.595 & 0.708 & 0.361 \\
& & $\mathrm{p}$ & $<0.001$ & $<0.001$ & 0.001 \\
& \multirow{2}{*}{ Spleen } & $\mathrm{r}$ & 0.587 & 0.586 & 0.432 \\
& & $\mathrm{p}$ & $<0.001$ & $<0.001$ & $<0.001$ \\
\hline \multirow{4}{*}{ Control } & & $\mathrm{r}$ & 0.708 & .659 & 0.535 \\
& \multirow{4}{*}{ Liver } & $\mathrm{p}$ & $<0.001$ & $<0.001$ & $<0.001$ \\
& & $\mathrm{n}$ & 54 & 54 & 54 \\
& \multirow{2}{*}{ Spleen } & $\mathrm{r}$ & 0.536 & 0.486 & 0.489 \\
& & $\mathrm{p}$ & $<0.001$ & $<0.001$ & $<0.001$ \\
\hline
\end{tabular}

Pearson's correlation coefficients were calculated. BMI: body mass index. Statistically significant at $\mathrm{p}<0.01$.

\section{DISCUSSION}

FMF is a repetitive autoinflammatory disease. The most common symptoms are fever, abdominal pain, arthritis/ arthralgia, and chest pain; more rarely, long-term febrile myalgia, erysipelas-like erythema, and orchitis are observed. FMF is associated with splenomegaly. However, the reticuloendothelial features of FMF have received little attention $(4,9)$. We evaluated spleen and liver sizes by age, height, and body weight in FMF patients during remission, and healthy controls. 
The levels of acute-phase proteins such as CRP, ESR, and SAA increase in FMF patients during attacks and usually return to normal during remission (10). However, subclinical inflammation continues during remission $(11,12)$, increasing the risks of anemia, splenomegaly, decreased bone mineral density, heart disease, and (especially) secondary amyloidosis (13, 14). Inflammation develops when certain cytokines are secreted by macrophages and monocytes (15).

The spleen is a platelet reservoir. Splenomegaly may be associated with increased hemolysis or may reflect a vascular, infectious, infiltrative, or inflammatory disorder. A significant correlation was evident between thrombocyte activation and splenomegaly in FMF children in remission. The mean platelet volume, which reflects platelet function and activation, was higher in FMF patients (16).

Splenomegaly extending past the Costa edge (i.e., $>5 \mathrm{~cm}$ ) has been reported in approximately $30 \%$ of FMF patients. Splenomegaly was usually not associated with amyloidosis but was linked to chronic inflammation (17). Korkmaz et al. (18) detected splenomegaly in approximately $25 \%$ of FMF patients (without amyloidosis) during attack-free periods. Ultrasonography revealed splenomegaly in $27 \%$ of patients with acute attacks and $13 \%$ of asymptomatic patients, but hepatomegaly in only $13 \%$ of asymptomatic patients (19). Dursun et al. (20) reported splenomegaly in $27.9 \%$ of FMF children in remission. Our figures were similar.

The phenotype-genotype relationship of FMF has been investigated extensively (20-23). Moradian et al. (24) found that all mutations were associated with hepatomegaly and splenomegaly. Exon 10 mutations associated with severe disease phenotypes (polyserositis, erysipelas-like erythema, splenomegaly, and vasculitis) reflected high-level M694V penetration. A homozygous M694V mutation has been linked to splenomegaly (25). We found that splenomegaly was usually accompanied by M694V and E148Q mutations.

Previous studies demonstrated correlations of longitudinal measurements of the liver, spleen, and kidneys with other bodily parameters and defined normal organ sizes $(26,27)$. Our longitudinal measurements were in line with such findings. As age, height, and weight increased, the spleen and liver sizes also increased (28). Safak et al. (26) evaluated schoolchildren and found no significant difference in organ size according to sex. Organ size was most correlated with body weight. Similarly, we found that organ size increased with age, height, and weight and did not differ according to. Age, height, and weight affected both liver and spleen sizes in FMF patients.
In the present study, FMF was the most important parameter affecting spleen length, thus more significant than age, height, or weight.

A diagnosis of FMF is based on clinical criteria. Elevations in the levels of acute phase reactants, indicative of inflammation, support diagnosis of an acute attack. Subclinical inflammation was apparent in 25\% of patients in remission (20). Ultrasonography is useful for evaluating the features of both an acute attack and remission. Splenomegaly during remission is considered to herald the development of an acute attack (20).

\section{CONCLUSION}

The spleen and liver dimensions were correlated with age, height, and weight. FMF affected spleen size (compared with that of healthy controls). To the best of our knowledge, this is the first study to compare the abdominal organ sizes of FMF patients in remission to anthropometric measurements. Splenomegaly may reflect low-level inflammatory activity during remission. In FMF patients, spleen size can serve as a marker of subclinical inflammation during remission.

\section{ETHICAL DECLARATIONS}

Ethics Committee Approval: The study was approved by the Gaziosmanpaşa University Clinical Researchs Ethics Committee (Date: 03.01.2016, Decision No: 16KAEK-060).

Informed Consent: Verbal and written informed consent was obtained from all participants who participated in this study.

Referee Evaluation Process: Externally peer-reviewed.

Conflict of Interest Statement: The authors have no conflicts of interest to declare.

Financial Disclosure: The authors declared that this study has received no financial support.

Author Contributions: All of the authors declare that they have all participated in the design, execution, and analysis of the paper, and that they have approved the final version.

\section{REFERENCES}

1. Ozen S, Bilginer Y. A clinical guide to autoinflammatory diseases: familial Mediterranean fever and next-of-kin. Nature Reviews Rheumatology 2014; 10: 135-47.

2. Yalcinkaya F, Cakar N, Acar B, et al. The value of the levels of acute phase reactants for the prediction of familial Mediterranean fever associated amyloidosis: a case control study. Rheumatology International 2007; 27: 517-22.

3. La Regina M, Ben Chetrit E, Gazparyan AY, Livneh A, Ozdogan H, Manna R. Current trends in colchicine treatment in familial Mediterranean fever. Clin Exper Rheumatol 2013; 31: 41-6. 
4. Aharoni D, N Hiller, Hadas-Halpern I. Familial Mediterranean fever: abdominal imaging findings in 139 patients and review of the literature. Abdominal Imaging 2000; 25: 297-300.

5. Barakat MH, Karnik AM, Majeed HWA, El-Sobki NI, Fenech FF. Familial Mediterranean fever (recurrent hereditary polyserositis) in Arabs-a study of 175 patients and review of the literature. Q J Med 1986; 60: 837-47.

6. Inal A, Yilmaz, M Kendirli, SG, Altintas, DU. Karakoc, GB. The clinical and genetical features of 124 children with Familial Mediterranean fever: experience of a single tertiary center. Rheumatol Int 2009; 29: 1279-85.

7. Yalcinkaya F, Ozen S, Ozçakar ZB, et al. A new set of criteria for the diagnosis of familial Mediterranean fever in childhood. Rheumatology (Oxford) 2009; 48: 395-8.

8. Ozen S, Aktay N, Lainka E et al. Disease severity in children and adolescents with familial Mediterranean fever: a comparative study to explore environmental effects on a monogenic disease. Ann Rheum Dis 2009; 68: 246-8.

9. Rimon D, Meir Y, Cohen L, Retroperitoneal lymphadenopathy in familial Mediterranean fever. Postgrad Med J 1989; 65: 776-8.

10. Oncu K, Yazgan Y, Tanoglu A, et al; Can serum fetuin-A be regarded as an inflammatory marker among patients with familial Mediterranean fever? Dig Dis Sci 2013; 58: 3212-7.

11. Akyol T, Düzenli T, Tanoğlu A. Evaluation of serum CXC chemokine ligand 16 (CXCL16) as a novel inflammatory biomarker or familial Mediterranean fever disease. Turk J Med Sci 2021; 51: 813-8

12.Lachmann H.J, Sengül B, Yavuzşen TU, et al; Clinical and subclinical inflammation in patients with familial Mediterranean fever and in heterozygous carriers of MEFV mutations. Rheumatology (Oxford) 2006; 45: 746-50.

13. Bilginer Y, Akpolat T, Ozen S. Renal amyloidosis in children. Pediatr Nephrol, 2011; 26: 1215-27.

14. Ben-Zvi I, Livneh A. Chronic inflammation in FMF: markers, risk factors, outcomes and therapy. Nat Rev Rheumatol 2011;7:105-12.

15. Baykal Y, Saglam K, Yilmaz MI, Taslipinar A, Akinci SB, Inal A. Serum sIL-2r, IL-6, IL-10 and TNF-alpha level in familial Mediterranean fever patients. Clin Rheumatol 2003; 22: 99-101.

16. Marzouk H, Lotfy HM, Farg Y, Rashed LA, El-Garf K. Mean platelet volume and splenomegaly as useful markers of subclinical activity in Egyptian children with Familial Mediterranean Fever: a cross-sectional study. Int J Chronic Dis 2015; 2015: 152616.

17. Livneh A, Langevitz $P$, Zemer D, et al. The changing face of familial Mediterranean fever. Semin Arthritis Rheum 1996; 26: 612-27.

18. Korkmaz C, Ozdogan H, Kasapçopur O, yazici H. Acute phase response in familial Mediterranean fever. Ann Rheum Dis 2002, 61:79-81.

19. Aharoni D, Hiller N, Hadas-Halpern I. Familial Mediterranean fever: abdominal imaging findings in 139 patients and review of the literature. Abdom Imaging 2000; 25: 297-300.

20.Dursun I, Gok F, Babacan O, et al. Are mean platelet volüme and splenomegaly subclinical inflammatory marker in children with familial Mediterranean fever? Health 2010; 2: 692-695.

21. Ureten K, Gönülalan G, Akbal E, et al. Demographic, clinical and mutational characteristics of Turkish familial Mediterranean fever patients: results of a single center in Central Anatolia. Rheumatol Int 2010; 30: 911-5.

22. Tunca M, Akar S, Onen F, et al. Familial Mediterranean fever (FMF) in Turkey: results of a nationwide multicenter study. Medicine (Baltimore) 2005; 84: 1-11.

23.Dusunsel, R, Dursun I, Gündüz Z, et al. Genotype-phenotype correlation in children with familial Mediterranean fever in a Turkish population. Pediatr Int 2008; 50: 208-12.

24. Moradian MM, Sarkisian T, Amaryan G, et al. Patient management and the association of less common familial Mediterranean fever symptoms with other disorders. Genet Med 2014; 16: 258-63.
25. Koné Paut I, Dubuc M, Sportouch J, Minodier P, Garnier JM, Touitou I. Phenotype-genotype correlation in 91 patients with familial Mediterranean fever reveals a high frequency of cutaneomucous features. Rheumatology (Oxford) 2000; 39: 12759.

26. Safak AA, Simsek E, Bahcebasi T. Sonographic evaluation of the normal limits and percentile curves of liver, spleen, and kidney dimensions in healthy school-aged children. J Ultrasound Med 2005; 24: 1359-64.

27. Konus OL, Ozdemir A, Akkaya A, Erbaş G, Celik H, Işik S. Normal liver, spleen, and kidney dimensions in neonates, infants, and children: evaluation with sonography. AJR Am J Roentgenol 1998; 171: 1693-8.

28. Warnakulasuriya DTD, Pathirennahalage P, Peries UC, et al. Ultrasonographic parameters of the liver, spleen and kidneys among a cohort of school children in Sri Lanka. Bmc Pediatrics 2017; 17: 192 .

29. Dogan TH, Başak M, Karatağ O, Değirmenci H, Ozkurt H. Sonographic evaluation of liver, spleen and kidney sizes in healthy children aged 0-14 years. Journal of Child Health and Diseases 2004; 47: 107-13 